\title{
METHOD AND MADNESS IN COPYRIGHT LAW
}

\author{
Dan L. Burk*
}

\section{INTRODUCTION}

Copyright law is a source of nearly endless scholarly fascination because of the paradoxes, the absurdities, the contradictions in its doctrines. Lewis Carroll's White Queen had nothing on copyright law. ${ }^{1}$ Copyright asks us to accept far more than six impossible, almost nonsensical assertions as part of its standard doctrine. Copyright asks us to believe, for example, that creative works have an existence independent of their embodiment ${ }^{2}$ that corporations, rather than people, can author documents $;{ }^{3}$ that computer code is a literary work, like poetry or novels; ${ }^{4}$ that artists have a special propensity to bungle their business affairs. ${ }^{5}$ The list seems nearly endless.

Perhaps we do not have to believe all of copyright's impossibilities before breakfast. But those of us who deal with copyright have to believe them, or at least pretend to accept them, all day long, day in and day out. As the Queen pointed out to Alice, believing impossible things takes practice. ${ }^{6}$ With enough practice, the impossible becomes commonplace. When that happens, when we stop seeing the impossibility in the impossible, we seldom stop to question, or at least marvel, over the exceptional ideas that we have come to accept. And when this happens in copyright, we overlook or ignore some truly startling assumptions that are foundational to the copyright system.

In this essay, I want to exercise the scholarly prerogative to examine one of those unexamined assumptions that lies at the center of a cluster of fundamental copyright doctrines. My subject is implicit in the way that copyright treats methods or processes, and we shall see that copyright has very special rules regarding methods or processes. Every student of copyright knows about these special rules, but the logic behind the rules, and the implications of that logic, have gone largely unexamined. I will look, hopefully with a fresh eye, at the assumptions about causality in copyright's treatment of methods, systems, and processes. I shall do so through the lens of a relatively recent series of cases dealing with copyright in

* (C) 2006 by Dan L. Burk, Oppenheimer, Wolff \& Donnelly Professor of Law, University of Minnesota. This article was originally delivered as the 2006 Clyde Lecture at the University of Utah S.J. Quinney College of Law. I wish to thank Professors Hillary Greene and John Tehranian, Professor and former Dean Scott Matheson, and their colleagues for the opportunity to develop the ideas presented here.

${ }^{1}$ See LeWIS CARROLL, Through the Looking-Glass and What Alice Found There, in The ANNOTATED ALICE 167, 251 (Martin Gardner ed., 1960).

217 U.S.C. $\$ \S 101,202$ (2006).

3 17 U.S.C. $\$ 201(b)$.

${ }^{4}$ H.R. REP. No. 94-1476, at 54 (1976), reprinted in 1976 U.S.C.C.A.N. 5659, 5667.

${ }^{5}$ See Stewart v. Abend, 495 U.S. 207, 207 (1990).

${ }^{6}$ See CARROLL, supra note 1 , at 251. 
valuation estimates, which ultimately implicate the methods for generating those valuations. I shall show that the copyright system incorporates a rather surprising set of notions regarding determinism and causality, and those concepts then play out in rather unexpected ways in a variety of related doctrines.

Now, we have not even gotten started and I have already invoked some rather formidable language, words like determinism and causality, which carry with them many centuries of philosophical baggage. We want to see what they are doing in the law of copyright, but in a relatively short essay we have neither the time nor the patience to unpack all of their baggage. Such a project could quickly spiral off into a discussion over the existence of free will and the implications of Laplace's demon. ${ }^{7}$ I hope to skirt that metaphysical abyss and concentrate instead on how they inform the structure of the copyright statute. We will be considering copyright's treatment of method, and you may initially get the sense that there is some madness to my method. But I believe you will see by the end that this is primarily due to a good deal of madness about methods in the law of copyright. And perhaps you will catch a glimpse of the impossible assumptions lurking beneath the surface of some copyright doctrines that we usually take for granted.

\section{SOME FOUNDATIONAL DOCTRINES}

We begin, as we so often do in copyright, with the Supreme Court decision in Baker v. Selden, one of the two or three pivotal decisions in American copyright law. ${ }^{8}$ Baker, you recall, involved the copying of printed forms that were intended to facilitate a method of accounting; the developer of the methods and of the forms, unsuccessfully asserted copyright in the forms. ${ }^{9}$ Baker is an iconic case for American copyright because it is situated at the intersection, at the crossroads if you will, of at least three, and perhaps four, key doctrines that are foundational to copyright, and which interact in a complex fashion that we will need to disentangle here. This doctrinal intersection is no accident, because these doctrines are closely intertwined and the facts of Baker present the limiting case.

The first of these doctrines is perhaps the most famous, although it is by no means certain that it should be, as it is not clear that it is in fact central to the holding of Baker. ${ }^{10}$ This is the idea/expression distinction, which perhaps surprisingly will concern us very little here. The idea/expression distinction is the first of several copyright doctrines that ensure copyright covers only expression, and we shall be chiefly concerned with some of the others rather than with this one. But this particular doctrine mandates that in copyright law, generalized ideas

7 "Laplace's demon" is a hypothetical entity capable of knowing the state of the universe at a given moment, and so of predicting the state of the universe in the next. See Roger HaHn, PierRe SimOn LAPLACE 1749-1827: A DETERMINED SCIENTIST 168 (2005).

${ }^{8} 101$ U.S. 99 (1879).

${ }^{9} I d$. at 99.

${ }^{10}$ See Pamela Samuelson, Why Copyright Law Excludes Systems and Processes From the Scope of Its Protection, 85 TEX. L. REV. 1921, 1924-28 (2007) (critiquing this reading of the Baker opinion). 
may be taken freely, and only particularized expression is protected by exclusive rights. ${ }^{11}$ You may write a story and call it Romeo and Juliet, and someone else may tell the same story and call it West Side Story. The general idea of these stories may be the same, but so long as the particular expression of the idea originates independently, the works are entitled to separate copyright protection, and no infringement has occurred.

Of more interest to us is the corollary of the idea/expression distinction, the concept of merger. In circumstances where there is only one way, or a very small number of ways, to express an idea, we say that idea and expression have merged - that the expression is coterminous with the idea. In such cases, copyright will not cover the expression, because to do so would be tantamount to copyrighting the idea. Multiple, alternative expressions of the idea would not be available to other creators, so that imposing copyright on the merged expression would monopolize the idea. One way to read Baker v. Selden is as an instance of merger: that the accounting forms were the only way to express the idea of the accounting method, such that the idea and expression merged, rendering the forms unprotectable in copyright. We shall see that this is perhaps not the best reading of the case, but it remains a very prevalent reading nonetheless. ${ }^{12}$

The second, most banal, and perhaps least defensible of the Baker doctrines also need not long concern us here. This is the line of authority holding that business forms are, if not per se unoriginal, at least universally suspect for copyright protection. ${ }^{13}$ A rule that forms are per se unprotectable is something of an oversimplification, and indeed a distortion, of the holding in Baker. The case does not stand for the proposition that forms are per se unoriginal, and certainly one can imagine original, expressive forms that could qualify for copyright. The conclusion that forms are per se unprotected may be the result of bad induction, as it confuses the particular with the general. The forms at issue in Baker v. Selden in fact were unoriginal and unexpressive, and the outcome in that case was surely correct from the application of the opinion's general principles to that specific instance. That need not mean that the outcome will be the same in every case involving forms.

Of course any copyright in original, expressive forms would be very "thin," that is to say, very limited. Copyright protection for forms is thin, and often nonexistent, not because forms as a genre are necessarily devoid of originality or of expression, but because any originality or expression is layered over a structure that is at its foundation functional. Forms are intended to collect and organize information, not to entertain or to edify in an aesthetic sense. Only the expressive portion of the form, if any, would be covered by copyright. The functional

${ }^{11}$ Harper \& Row Publishers, Inc. v. Nation Enters. 471 U.S. 539, 556 (1985).

${ }^{12}$ See Pamela Samuelson, The Story of Baker v. Selden: Sharpening the Distinction Between Authorship and Invention, in INTELLECTUAL PROPERTY STORIES 159, 177 (Jane C. Ginsburg \& Rochelle Cooper Dreyfuss, eds., 2006).

${ }^{13}$ See, e.g., Bibbero Sys. Inc. v. Colwell Sys. Inc., 893 F.2d 1104, 1106-07 (9th Cir. 1990); see also 37 C.F.R. § 202.1(c) (2007) (Copyright Office rule precluding copyright registration of blank forms). 
structure of the form lies outside of copyright, available for appropriation, and in most cases, it would be a trivial exercise to strip off the veneer of protected expression so as only to take the unprotected framework of the form.

So the bias against copyright protection for forms in fact derives from a third line of authority that springs from Baker, and this doctrine demands rather more of our attention. This line of cases deals with the principle of functionality. Copyright covers expressive works, and not functional or utilitarian works. We must be somewhat cautious with this terminology, because all copyrightable subject matter has a use, a utility, or in a very broad sense performs a function. ${ }^{14}$ Novels and paintings and poetry are useful to entertain and enlighten their audience, they perform a communicative function of telling the audience something about the author, and the world, and if the art or literature is good art or literature, it ought to tell the audience something about themselves. But utility in copyright is not concerned with such informational or aesthetic "uses;" rather it is practical or operational "uses" that are excluded from the copyright protection.

A particularized version of this principle appears in the copyright statute, as the "useful article" doctrine under section 101 of the statute. ${ }^{15}$ That definition of useful article addresses the subject matter category of pictorial, graphic, and sculptural works; the statute states that when such a work entails both aesthetic and functional features, then only the expressive features that are physically or conceptually separable from the functional features will be protected under copyright. ${ }^{16}$ If the functional features are not separable from the expressive features, then the whole work is deemed functional, and so unprotectable in copyright. The statute further defines a useful article as one having a utilitarian purpose other than to convey information or to portray itself. ${ }^{17}$ That language is intended to deal with the definitional problem that we have already identified: paintings and sculptures have a use, but the function is to convey information or to portray themselves. They are not useful in the functional sense that we have been considering.

The "useful article" section of the statue contemplates a particular instance of functionality, involving the category of pictorial, graphic, and sculptural works. But the Baker opinion articulates a more general version of that principle, beyond the category of pictorial, graphic, and sculptural works. It says that items that perform functions or have uses other than expression belong in the patent system, not the copyright system. ${ }^{18}$ And that of course is where the Supreme Court in Baker told Selden he ought to go with his accounting method, to the Patent Office, although ironically the Patent Office at that time was unlikely to grant a patent on a

${ }^{14}$ See Dennis S. Karjala, A Coherent Theory for the Copyright Protection of Computer Software and Recent Judicial Interpretations, 66 U. CIN. L. REV. 53, 57-58 (1997) (distinguishing "useful" works from "functional" works).

1517 U.S.C. $\$ 101$ (2006).

${ }^{16} I d$.

${ }^{17} I d$.

${ }^{18}$ Baker v. Seldon, 101 U.S. 99, 102 (1879). 
business method because of the view that such methods failed some of the other criteria for patentability. ${ }^{19}$

It is important to note that the useful article portions of the statute also signal a type of merger rule for functionality. The rule that functional and expressive features must be physically or conceptually separable in order for the latter to receive any copyright protection parallels the merger rule in the idea/expression doctrine. If function and expression are merged, if they are not physically or conceptually separable, then the entire work is excluded from copyright. This points to another and important way to read Baker: that whatever expression there may have been in the accounting forms, it was merged with their function, and so off-limits to copyright. This may indeed be the best way to read Baker v. Selden. It might be said that because the accounting forms were the only way to express the accounting system, that idea and expression had merged. But it might better be said that because the accounting forms were the only method of performing the accounting method, expression and function had merged.

Indeed, one implication of Baker is that we can often recognize functionality by the criterion of merger; by constraint upon methodology. We assume that there are multiple, perhaps nearly infinite ways of expressing the ideas in art, music, or poetry. But when there is only one way, or a limited number of ways, to achieve a certain result, then it is likely we are no longer talking about something that is expressive, but are talking about something that is utilitarian or functional. Trademark law, which also excludes utilitarian features of a mark from protection, has a similar rule for recognizing utility for functionality. ${ }^{20}$ The constraint on alternatives signals the presence of functionality.

In a case such as Baker, where the forms were the only way to practice the accounting method, the constraint on alternatives is a point of convergence with the idea/expression doctrines, but may not always be so. For example, in the Lotus $v$. Borland case, where Lotus had copied computer menu commands from Borland's user interface, the court concluded that there had not been idea/expression merger, but there had been functionality merger. ${ }^{21}$ The court noted that there were many possible substitutes or alternatives for the "copy" command in the command menu: Lotus could have changed the command to "replicate" or "duplicate" or something of the sort. ${ }^{22}$ So there were other possible modes of expression. But as a practical matter, there was only one viable, functional way of indicating this command, which was to use the standard command that users would recognize. Having learned one command structure, users would become confused or would incur the personal expense of relearning new commands each time they tried to change products. The benefits of standardization created a functional merger, if not an expressive merger.

${ }^{19}$ See Dan L. Burk, Patenting Speech, 79 TEX. L. REV. 99, 142 (2000).

${ }^{20}$ See In re Morton-Norwich Prods., Inc., 671 F.2d 1332, 1337 (C.C.P.A. 1982).

${ }^{21} 49$ F.3d 807, 815 (1st Cir. 1995), aff'd by an equally divided Court, 516 U.S. 233 (1996)

${ }^{22}$ Id. at 811 . 
Even though this functionality analysis is integral to the Borland decision, and even though the Borland decision relied very explicitly on the Baker decision, it does not rely on Baker for quite this proposition in quite this way. Lotus v. Borland brings us to the fourth, and final stream of copyright doctrine that flows from Baker v. Selden, which is also found in the title of this article. And that is the doctrine regarding processes and methods of operation. The Borland court held that the user interface commands, whether expressive or not, were the embodiment of a method or process for operating the computer. ${ }^{23}$ The court compared the interface commands, quite rightly, to the accounting forms in Baker, which were the embodiment of an accounting process. ${ }^{24}$ The forms were themselves the method. And the copyright statute explicitly excludes processes and methods of operation from the protection of copyright.

Now you may notice two corollaries of this holding, neither of which should be surprising given what we have said so far. The first is that we are again talking about a sort of merger doctrine. ${ }^{25}$ The menu commands in Borland may have been expressive, or at least they were the result of choosing or selecting among different possibilities for the user interface. We shall say more about that in a moment. The accounting forms in Baker were really not expressive, as they were rather bare bones, but they could have been. Yet in neither case were the commands or the forms protectable, because protecting them would have been tantamount to protecting the method or process that they embodied. This is the rationale of merger. If the expressive part of a work can be separated from the method, or from the function, or from the idea, then copyright can cover the expression separately. But if the expression cannot be separated or disentangled from the method, or from the function, or from the idea, then the expression has no place in copyright.

The second corollary you may notice is that the prohibition on copyright for methods and processes is intimately bound up with the prohibition on copyright for functional or useful articles. Processes are by definition functional, they are functions. Creative works may be the products of processes, they may be the output. Or they may be the input into processes. Such inputs and outputs may be expressive or they may be utilitarian, and the relationship between functional processes and their non-functional products is troublesome. If you recall the definition of a useful article, you will recall that it excludes works that convey information or portray themselves. ${ }^{26}$ And as you can see those are characteristics defined by processes - conveying, portraying-so there is the question of what to do with processes that communicate information or portray expression. This is a bit of a problem, and we shall say more about that in just a moment as well.

But for the moment it may be best to recognize the relationship between process and functionality in the terms set out by the Baker decision. Recall that

${ }^{23} \mathrm{Id}$. at 815 .

${ }^{24} \mathrm{Id}$. at $816-17$.

${ }^{25}$ See Alan L. Durham, Speaking of the World: Fact, Opinion, and the Originality Standard in Copyright, 33 ARIZ. ST. L.J. 791, 807-08 (2001).

${ }^{26} 17$ U.S.C. $\$ 101$ (2006). 
Baker stands for the proposition that functional subject matter belongs in the patent system, and not in the copyright system. It also stands for the proposition that processes and methods belong in the patent system and not in the copyright system. Just as the copyright statute explicitly excludes processes and methods from its subject matter, so the patent statute explicitly includes processes and methods within its subject matter. Processes have their home in the patent statute, with other utilitarian creations. The Baker opinion draws a clean line between patent and copyright, but we shall see that the line is perhaps less clean than it once was.

\section{FACTS AND FICTIONS}

We have now seen how the Baker decision and its progeny set the fundamental copyright doctrine on methods and processes, and that in turn sets the stage for us to think about the meaning of those doctrines in the copyright system. I said at the beginning that the objective of this essay is to look at certain assumptions embedded in the law of copyright, and that our entry point to that discussion is a set of very troubling opinions beginning with the Second Circuit decision in CCC Information Services, Inc. v. Maclean Hunter Market Reports, Inc. ${ }^{27}$ We want to examine how the Baker doctrines play out in some of these cases; we frankly want to see where these opinions have gone wrong. These opinions are like our treasure map; they mark the spot where the interesting concepts are buried. It is the anomalies in these opinions, the inconsistencies, that show us where to start digging.

In $C C C$, the allegedly infringed work was a compilation of used car valuations, the "Red Book," which was useful for selling or purchasing used automobiles, and particularly useful for payment estimates by automobile insurance adjusters. ${ }^{28}$ The accused infringer had extracted the valuations from the print version of the Red Book and provided them on-line as electronic reports. ${ }^{29}$ When sued for infringement, the electronic service argued that the valuations were facts, statements about the prices that would be paid for various automobiles, calculated by taking into account relevant factors such as price variations by region, by condition of the automobile, by make and by model, and so on. ${ }^{30}$ Since it is black letter law that only original expression, and not facts, is protected under copyright, that would mean that copying the valuations was not a taking of protected expression, so that copying the valuations was not infringement.

While this argument was accepted by the trial court, on appeal the Second Circuit held that the valuations constituted original expression. ${ }^{31}$ The appellate court reached this conclusion on the basis of the choices that had been made in

\footnotetext{
${ }^{27} 44$ F.3d 61 (2d Cir. 1994).

${ }^{28} I d$. at 63.

${ }^{29}$ Id. at 64.

${ }^{30} \mathrm{Id}$.

${ }^{31}$ Id. at 67.
} 
developing the valuation formula; for example, the choice to divide the nation into a certain number of geographic regions for valuation, or the choice to compare vehicles based on 5,000 mileage increments. ${ }^{32}$ According to the court, such selection among different possibilities meant that the values in the Red Book were not factual statements about the value of automobiles, or arithmetic derivations from available data, but were only a "loose judgment" about automobile values and were "approximate and original," rather than "mechanical" or "historical.,"33 The values were the result of choices, and so were expressive, and so constituted the proper subject matter of copyright.

This holding is troubling, the more so because it is not an isolated instance; there have been several cases with a similar profile. For example, in CDN, Inc. v. Kapes, the defendant published on his Internet site values for rare coins, which were drawn in part from numismatic values published by the plaintiff. ${ }^{34}$ As in the case of the CCC automobile valuations, the CDN coin valuations were arrived at by a process of combining and evaluating relevant pricing factors, such as the type, condition, and age of coins, the results of recent auctions and sales, and other movements in the market. ${ }^{35}$ As in $C C C$, the defendant in $C D N$ argued that no protected expression had been taken because the published values were facts. ${ }^{36}$ The trial and appellate courts disagreed, relying upon $C C C$ to conclude that the values were judgments, that they were the creative products of choices made by the compilers of the valuations. ${ }^{37}$ As with the automobile valuations, the coin values were found to constitute original expression, and so copying them constituted infringement.

But a bit of reflection reveals that these are quite disturbing results. First, it seems that the supposedly "original" aspects of the values for used cars or for coins were the kind of "choices" dictated by the desire for accuracy, for correspondence with fact. This seems clear from the nature of the product being sold: the compilation of values. If the values given in the compilation were truly original, truly idiosyncratic, then what use could they be to those who want to know the value of the used cars or rare coins they are buying and selling? Would the compilers of the valuation books really sell very many books if they represented that their valuations were based on creative guesswork, that they chose the geographic regions for their aesthetics, or that the values of the items listed were based on an artistic whim? Would the purchasers of such books care to rely on valuations that bear no relation to the prices and valuations that are actually the basis for exchange in the marketplace?

On the contrary, it seems obvious that the valuations are themselves valued for their accuracy, for their predictability, for their determinacy. The factors that

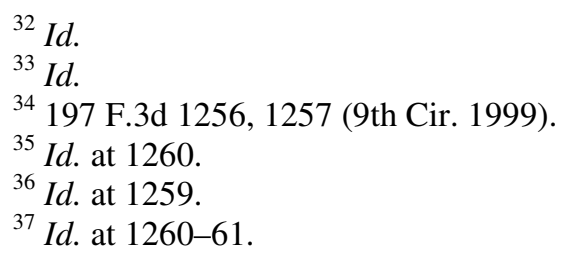


went into the valuations were certainly chosen to yield the best possible prediction of market value. The entire point of the "Red Book" or of a numismatic catalog is that the valuations should reflect as closely as possible the actual state of the market for used cars or rare coins, so that the "choice" of valuation factors is dictated by circumstances beyond or outside the original expression of the compilers. This is always the case for factual works. The cartographer has the "choice" of depicting measuring distances in ells or furlongs, but such a map is unlikely to be useful or appealing to modern users - the cartographer will almost certainly use miles or kilometers. For that matter, the cartographer has the "choice" of depicting the world as flat, rather than spheroid but such a map depicts what we would understand to constitute fantasy rather than reality. ${ }^{38}$ Such "choices" are illusory for the creators of works that are not flights of fancy, but intended to correspond with reality. Or in other words, the valuations of cars and coins, like the measurements and features on a map, were meant to be what we would understand to be facts.

Even if the valuations were estimates, or had some range of deviation or coefficient of error, this would not differentiate them from any other scientific measurement that yields a best approximation. The careful scientist recognizes the imperfections of measurement, and puts error bars on her graphs. Even through the background noise of unrelated but inseparable phenomena, or against the impediments of human and instrumental error, such measurements are intended to reflect something about the state of the world. And so, too, are the numbers valuing coins and used cars. The judgment that a spectrophotometer will yield better results than a scintillation counter, or that a 1969 Dodge Dart will likely sell for $\$ 100$ more south of the Mason-Dixon line than it will to the north, is not at all the same thing as the judgment that a fictional character like Sherlock Holmes will be depicted to play the violin rather than the bassoon.

It is worth noting at this point that copyright law treats expression that is represented as factual as being factual-the so-called copyright estoppel doctrine. ${ }^{39}$ If you claim that your theory of history or cosmology is a fact, then you are stuck with that assertion, ${ }^{40}$ - which is to say, that you cannot protect that datum in copyright, because copyright covers original expression, not facts, and we take you at your word that your datum is factual. If it is a fact, it is not protected by copyright; if it is protected by copyright, then it can't be a fact. You can't have it both ways, and courts will hold you to your original representation.

Unless, perhaps, you are in the Second Circuit, where they have decided that some facts aren't factual. In a feat of legal gymnastics intended to save

38 See, e.g., TERRY PrATChETt, THE COLOUR OF MAGIC (1983) (depicting "Discworld," a fictional flat world).

${ }^{39}$ See Thomas F. Cotter, Gutenberg's Legacy: Copyright, Censorship, and Religious Pluralism, 91 CAL. L. REV. 323, 345 (2003) (discussing copyright estoppel).

${ }^{40}$ See, e.g., Urantia Found. v. Maaherra, 114 F.3d 955, 958-59 (9th Cir. 1997) (text purportedly received from extraterrestrial beings unprotected by United States copyright); Nash v. CBS, Inc., 899 F.2d 1537, 1541 (7th Cir. 1990) (historical theory unprotected by copyright). 
compilations like the Red Book from an unavoidable idea/expression paradox, ${ }^{41}$ the Second Circuit held that what it calls "hard" or objective ideas may be subject to the idea/expression doctrine, but that "soft" or subjective ideas, infused with opinion, are not. ${ }^{42}$ And of course they found the Red Book automobile valuations to be "soft" opinionated ideas. ${ }^{43}$ What the Second Circuit calls "hard" or objective ideas, we generally call facts. We should note first that this runs all the copyright exclusions from Baker together into one muddle: the process or method of producing the valuations is an "idea," the functional valuations themselves are an "idea" - indeed everything this side of Plato's cave ${ }^{44}$ is an "idea." And second, this maintains copyright in the $C C C$ valuations by distinguishing them into a class of statements about the world that require judgment and creative selection-sort of subjective facts, if you will.

But this distinction proves far too much. The Second Circuit spoke more truly than it knew. Postmodernists would tell us, quite properly, that all facts involve judgment and creative selection. As the late Jacob Bronowski was so fond of pointing out, there really are no measurements, only judgments. ${ }^{45}$ When you round the value of $\pi$ off to 3.141592654 , you have made a judgment that it is the first nine decimal places that matter, and that the rest don't. When you look at stars through an optical telescope, you have made a judgment that it is the wavelengths of light between 400 and 700 nanometers that matter, and that the rest of the electromagnetic spectrum doesn't - if you were to use a radio telescope to look at other wavelengths, you would get quite a different picture of the phenomenon you are observing. That is why science, fact-finding, is a creative endeavor, a human endeavor: because it requires judgments about what matters, which in turn require a model or viewpoint about the universe to inform those judgments, and the construction of such a model or viewpoint is quintessentially an act of creation. ${ }^{46}$

This is a theme that I will return to a bit later. For now it is important to see that if we follow the logic of judgment too far, then there are no facts that lie outside the copyright system. Everything becomes expression, and every measurement is covered by copyright. That cannot be right. The corollary of course is that the copyright system has a very pronounced view about what constitutes a fact. The statute says that there is something called a fact, and that facts are not covered by copyright. Facts exist independently in the universe, waiting to be found or discovered. Copyright covers original expression, and

${ }^{41}$ See Dan L. Burk, Expression, Selection, Abstraction: Copyright's Golden Braid, 55 SYRACUSE L. REV. 593,594-95 (2005).

${ }^{42}$ CCC Info. Servs., Inc. v. Maclean Hunter Mkt. Reports, Inc., 44 F.3d 61, 71-73 (2d Cir. 1994).

${ }^{43} I d$. at 73.

${ }^{44}$ See Plato, The Republic 220-25 (G.R.F. Ferrari ed., Tom Griffith trans., Cambridge University Press 2000).

${ }^{45}$ See JACOB BRONOWSKI, The Abacus and the Rose: A New Dialogue on Two World Systems, in SCIENCE AND Human VAlues 77, 88-91 (Harper \& Row rev. ed. 1965).

${ }^{46}$ JaCoB BRonowski, The Creative Process, in A SENSE OF THE Future 6, 11 (1977). 
whatever facts are, they are not original expression. ${ }^{47}$ And the cases like $C C C$ and $C D N$ tell us that this is because facts do not involve judgments or choices, they do not originate in the decisions of an author. We know that on any sensible understanding of science this assertion is manifestly untrue, but we shall have to accept it for the moment.

However, you should see that the definition of fact as divorced from choice or judgment is not only manifestly untrue, it should also be decidedly familiar. It is the same criteria we have seen before in deciding what is to be excluded from copyright, in deciding what is original and expressive and what not. Recall what we have already said about the intersecting doctrines in Baker v. Selden. We know that idea and expression have merged, and have become unprotectable, when the there is only one or a limited number of ways to express the idea. We know that function and expression have merged, and have become unprotectable, when there are utilitarian constraints on the available options to achieve the instantiation of the work. We know that expression and process have merged, and so become unprotectable, when the expression is dictated by function, as it was for Selden's accounting forms. So it should not surprise us if courts are defining another category of excluded subject matter-facts-in terms of the availability of alternative expression.

\section{THE PROBLEM OF PROCESS IN COPYRIGHT}

To this point we have seen that cases such as $C C C$ and $C D N$ adopt the rather dubious view that the valuations found in automobile and numismatic catalogs are not facts, but are a form of creative expression. This conclusion in turn rests upon a particular view of facts embedded in the copyright system. When dealing with matters extrinsic to the author, with facts, copyright assumes that their expression is dictated by the state of the universe, and that there is not a large or infinite number of ways to express those concepts-or at least, not a large number of ways to express them accurately. This is why the copyright in factual compilations, such as maps, is "thin." depict a river or mountain on a map, changing the colors or choosing the symbols to mark the particular geographic feature. But when the mapmaker becomes sufficiently creative with the location of the features, with their relationships to one another, the map ceases to reflect the state of reality-we then have a map of some other reality, of Elfland, or of Middle-earth, which is highly creative and garners a high degree of copyright protection, but which is not useful in navigating Poughkeepsie. $^{49}$

${ }^{47}$ See Durham, supra note 25, at 802.

${ }^{48}$ See Dennis S. Karjala, Copyright in Electronic Maps, 35 JURIMETRICS J. 395, 413 n.65 (1995).

${ }^{49}$ Cf. Ursula K. LeGuin, From Elfland to Poughkeepsie, in The Language Of The Night: ESSAYS ON FANTASY AND SCIENCE FICTION 73, 74 (Susan Wood ed., G.P. Putnam's Sons 1979) ("[T]he point about Elfland is that you are not at home there. It's not Poughkeepsie."). 
We have also seen that this assumption that original expression can take multiple forms, that it is not constrained to a single embodiment, is a standard doctrinal assumption in copyright, underpinning for example the idea/expression distinction and the concept of merger. In copyright we normally assume that there exist a large, possibly infinite number of ways to express a particular idea. But where the number of possible ways to express an idea is highly constrained, to the point that only one or a very small number of expressive modes are available, then the danger exists that protecting that expression would be tantamount to protecting the idea, and we refuse to protect the expression. The same is true where the constraints are functional. Where there is a large, possibly infinite, number of ways to reach a particular outcome, the courts take that as an indicator of originality, of expression. Where the options are constrained to one or a few possibilities, this is taken as an indicator of functionality and copyright is precluded.

Now I wish to concentrate for a moment on this reasoning as it applies to processes or methods, as you would expect from the title of this article. For all the talk of idea/expression merger in these opinions, they encompass at their core a process issue as well. This should be clear from the courts' criteria for declaring the valuations to be expressive. The courts focus on the valuation factors selected, the decisions about input that result in the final numerical result. This is to say that the courts focus upon the method, on the algorithm used for determining the value of a car or of a coin, for determining whether the result qualifies for copyright. This approach ties the output of the process, the valuation of the car or coin, to the method by which it was produced, as a matter of definition. And that should give us pause. Baker tells us that methods are not protected under copyright, and that there are instances where a method is instantiated as expression, which precludes the copyright of this expression. Only where a method and its expression are clearly separable can copyright protect the latter.

So the result in these cases is troubling for a second reason, which is the very real presence of a process or method that may be swept up into copyright protection. The $C C C$ opinion rejects the idea that it might be doing what Baker $v$. Selden forbids: protecting a process incident to protecting expression that is bound up with that process. The court claims that the Red Book valuations "explain nothing, and describe no method, process, or procedure." ${ }^{, 50}$ The court assumes that the valuations and the process that produced the valuations are conceptually separable, that the latter can be covered by copyright without covering the former. $^{51}$

But the valuation number is the end product of a method, the tip of a methodological iceberg. Protecting the end product as a matter of copyright effectively protects the method by which that end-product was generated, especially if the method involves the creativity that the court attributes to it. There may be several ways to measure the current temperature, but we expect them to

${ }^{50}$ CCC Info. Servs., Inc. v. Maclean Hunter Mkt. Reports, Inc., 44 F.3d 61, 73 (2d Cir. 1994).

${ }^{51}$ Id. at $72-73$. 
converge on a particular result, or range of results, conforming to the state of the universe. But if the valuation of an automobile or coin is indeed an idiosyncratic, creative product, then we would not expect multiple methods to yield the same result except perhaps by sheerest happenstance-there is no objective result that they need conform to. A creative, idiosyncratic result arises from a creative, idiosyncratic, and likely singular, process. If the protected expression stems from creative choices then it follows that it is ultimately those choices that are being protected by copyright.

Of course this argument also proves too much-or does it? Remember the question, which we reserved before, as to what we should do with processes that portray a work or convey information. Here it is again, or at least its first cousin. A particular painting represents the endpoint or culmination of the process that produced it, the application of daubs of pigment to a canvas or other surface. A particular sculpture represents the endpoint or culmination of the process that produced it; chiseling away fragments of stone; accreting successive bits of clay or wax; smelting, pouring, and cooling alloys in a mold. Protecting the result of such processes in some sense protects the process that culminated in exactly that product. If we say that this Picasso painting or this Moby soundtrack is protected by copyright, then we are in effect saying that the process which results in that painting or soundtrack is also swept up into that copyright. Indeed, we may be protecting a suite of processes, as any process that reproduces that particular painting or soundtrack is precluded by copyright, whether the process is painstakingly reproducing the Picasso image by hand or whether the process is simply scanning and printing the image. The copyright statute does not say that it covers the process by which a work is produced, but if the process necessarily produces the work, and producing the work is infringement, the process is precluded along with the infringing product.

The caveat of course is that the process is precluded from copyright unless it independently recreates the protected work, that is, unless no copying is involved. For infringement to occur, there must be a causal connection between an authorized copy of the work and the production of an unauthorized copy of the work. Sometimes we infer such a connection as an evidentiary matter. ${ }^{52}$ But whether the connection is explicit or inferred, the precluded process must be one that takes someone else's original expression as an input and maintains some substantial portion of that expression as an output. ${ }^{53}$ Copyright prohibits unauthorized copying, or reproduction of the work; if there is no copying, there cannot be a violation of the right of reproduction. So independent re-creation is a defense to a claim of copyright infringement. But we assume both as a matter of

${ }^{52}$ See Arnstein v. Porter, 154 F.2d 464, 468 (2d Cir. 1946).

${ }^{53}$ We might note in passing that processes which, without authorization, take original expression as an input and produce some other original expression as an output have been held to constitute fair use of the input expression. See Sony Computer Entm't, Inc. v. Connectix Corp., 203 F.3d 596 (9th Cir. 2000); Sega Enters. v. Accolade, Inc. 977 F.2d 1510 (9th Cir. 1992); Vault Corp. v. Quaid Software Ltd., 847 F.2d 255 (5th Cir. 1988). 
evidence and as a matter of causality that the chances of independently re-creating a Picasso painting or a Moby soundtrack, or Keats' Ode on a Grecian Urn, ${ }^{54}$ are vanishingly small.

And it is exactly that assumption about the probability of independent recreation, the assumption that original expression is rare, unique, and particular to an author, and the corollaries to that assumption, that are key to the treatment of process in copyright. I have said that the court in $C C C$ essentially classified works according to the nature of the process that produced them. I have also just said that we do something of this sort as a general matter in deciding the causality of infringement; we say some processes imbue their products with originality, and others do not. A process which only copies another work has a determined outcome; it will result in the same expression that it emulates. A process that produces something undetermined, either independent of a given model or idiosyncratically while trying to reproduce a model, in whole or in part, is not merely reproduction. We rely upon the distinction between determined and undetermined outcomes to decide what is original expression and what is not.

So we can see, for example, a reliance upon the idiosyncratic variations of the mezzotint process in the famous Alfred Bell \& Co. v. Catalda Fine Arts, Inc. opinion. ${ }^{55}$ In that case, the plaintiff had produced mezzotint engravings, reproductions of Old Master paintings, such as by Rembrandt. The accused infringer had produced unauthorized second generation engravings, copying from the first generation engravings. Any expression copied from the Old Masters lay in the public domain, and could be taken, second-hand so to speak, from the mezzotint just as they could have been taken directly from the public domain Rembrandt. So the only question was whether anything original had been added to the mezzotint that might have been taken by the subsequent copyist. The court held that something original had been added to the first generation engravings, that the engraving process reflected idiosyncrasies unique to the engraver, such as stray lines and other variations. ${ }^{56}$ Copying those variations from the first generation engravings was an infringing appropriation of original expression.

One has to wonder a bit about that holding; if the purpose of the engraving was to produce as faithful a reproduction of the public domain work as possible, then the engraver's choices were directed toward producing a reproduction with nothing original, and nothing for copyright to protect. Some more recent cases involving more sophisticated reproduction technologies have held just that; that a high fidelity reproduction of a public domain work leaves nothing to be added to the reproduction that can be called original. ${ }^{57}$ Mistaken or inadvertent deviations from faithful reproduction hardly seem original choices of the sort that copyright

\footnotetext{
${ }^{54}$ Sheldon v. Metro-Goldwyn Pictures Corp., 81 F.2d 49, 54 (2d Cir. 1936).

55 191 F.2d 99 (2d Cir. 1951).

${ }^{56} \mathrm{Id}$. at $102-03$.

${ }^{57}$ See, e.g., Bridgeman Art Library, Ltd. v. Corel Corp., 36 F. Supp. 2d 191, 200
} (S.D.N.Y. 1999). 
should protect. ${ }^{58}$ It may be that the court was really trying to protect the labor that went into creating the mezzotints, and that this would be prohibited under more recent Supreme Court decisions. ${ }^{59}$ But if we take the opinion at face value, the court in Alfred Bell found that something was added, that the reproduction was not made with perfect fidelity. Or in other words, that the outcome of the process was not pre-determined; the process could result in multiple possible end products.

By the same token, a process that is seen to constrain the copyist to an unoriginal outcome entails no original expression, so that a second generation copy would not be infringement. This was the situation, you may recall, in L. Batlin \& Son, Inc. v. Snyder. ${ }^{60}$ The work at issue in Batlin was a mass-produced replica of a much older cast metal bank in the form of an "Uncle Sam" figure. The cast metal bank, if it ever had copyright protection, had fallen into the public domain and became the model for an inexpensive plastic replica. The mass-produced version differed in certain minor respects from the cast metal original, in part due to differences in the method of manufacture - certain details of the figure could not be replicated, or could only be replicated with less definition, when produced by the injection of polymer plastics into a mold.

When the plastic replica of the bank was itself copied by another manufacturer, the first manufacturer sued unsuccessfully for copyright infringement. ${ }^{61}$ As in Alfred Bell, the question was whether anything protectable existed in, and had been taken from, a reproduction of a work that lay in the public domain. Yet in Batlin, unlike Alfred Bell, the court held that while the second manufacturer had certainly copied, the copying had not taken any original, protectable expression. ${ }^{62}$ Any expression copied from the cast metal original to the plastic replica was of course unprotectable as having fallen into the public domain, and could be taken freely by the second manufacturer, whether directly from the cast metal bank or indirectly as passed along in the plastic replica. Consequently, the first manufacturer had to point to the differences from the cast metal original as the only candidates for original expression that might have been copied. ${ }^{63}$ But those differences were held to be either so trivial as to lack originality, or to have been dictated by the nature of the manufacturing process - in other words, to have been the result of a functional process. ${ }^{64}$

Now were there no choices made, no selections, in producing the Batlin novelty bank? Apparently none that the court believed were unique or idiosyncratic or original to the creator. The variations from the public domain bank were held to result from the characteristics of the materials used in molding the polymer-not from a creative choice of the designer. To be sure, the designer

${ }^{58}$ See Alan Durham, The Random Muse: Authorship and Indeterminacy, 44 WM. \& MARY L. REV. 569 (2002) (arguing that inadvertent creations are not works of authorship).

${ }^{59}$ See, e.g., Feist Publ'ns, Inc. v. Rural Tel. Serv. Co., 499 U.S. 340 (1991).

${ }^{60} 536$ F.2d 486 (2d Cir. 1976).

${ }^{61} \mathrm{Id}$. at $487-88$.

${ }^{62} I d$. at 492.

${ }^{63} I d$. at 489 .

${ }^{64} \mathrm{Id}$. 
made choices: the choice to imitate the cast iron public domain bank, and to do so using polymer plastics. I suppose the court in $C C C$ might consider those choices creative choices, although the choice of materials was likely dictated by the cost of manufacturing and clearing price for such replicas in the market, so it seems unlikely that the bank manufacturer really had a very free hand in those decisions. And once the decision was made to use an injected polymer manufacturing process, then certain features of the bank resulting from the process were determined.

That kind of determination will be the case whatever production process is employed. Just as certain results are determined once you have decided to replicate a bank in polymer plastic, so certain results will be determined once you have decided to estimate the market value of used cars. For that matter, it seems likely that certain results are determined once you decide to replicate Rembrandt drawings as mezzotint. A certain mode of production might be chosen to replicate novelty banks or mezzotints due to its economic features, or due to its esthetic features, but in either event it will give rise to certain product characteristics that are determined by the use of those particular input materials in that particular process.

\section{DEGREES OF FREEDOM}

By now, I hope it has become plain that there is a commonality among the categories of subject matter that we have considered as being excluded from copyright. They are identified and defined by criteria that are shared by the doctrines we have reviewed. The common thread here is that of determinism; courts declare that the law of copyright does not protect expression that can only be instantiated in a single, determined way. Neither does it protect processes or methods, which yield predictable, determined outcomes. And it treats the universe as a sort of machine, as a collection of processes that generate deterministic results, which it designates facts, and which it refuses to accept as the subject of copyright because they are determined, and not originated from an author.

The language of determinism, or of determination, carries with it some connotative danger. Perhaps we should use the term "monovalent" to describe this kind of process, in order to avoid the philosophical morass of causality and predestination and such. We need not make a philosophical declaration about the causal order of the universe in order to consider actions that converge upon a determined result. Our concern is with outcomes localized in space and in time; we need not trace matters back to the Big Bang, or to Genesis, or to the hatching of the Cosmic Egg. We are considering conditions tied to a particular result, processes that, if I may borrow a term from statistics, are constrained or are singular in their degrees of freedom.

Neither should we become distracted by the problem of inevitability. The linkage of an outcome to a previous set of conditions need not necessarily be predictable to be determinate. We may have incomplete information about the initial conditions that produced a certain result, but that is a failure of human 
capacity, not of determinacy. And of course even predictable processes can go wrong; Murphy's Law may divert processes into unexpected outcomes. But in such a case we are of course considering an outcome causally related to a different process than the one we had considered initially, the unexpected process rather than the expected process.

We need only recognize that copyright doctrine contemplates an obligatory sort of causality for non-expressive subject matter. Copyright separates out subject matter that is monovalent, or determined, or singularly constrained, in its outcome. Setting aside the very interesting but rather sticky philosophical ramifications, this doctrine implicitly adopts a determined causality, assumes that a particular result is causally related to a particular action, that the state of the universe at one moment is determined by the state of the universe in the previous moment, and will in turn determine the state of the universe in the moment to come. I have said that this is effectively a process-based definition of expression. The presence of a process implies the presence of an apparatus for executing that process. In copyright, the universe is that machine.

This is of course the logic of science. We design experiments to force the universe to a resolution between alternatives, and we assume that the state of the universe at the end of the experiment is deterministically correlated to the state of the universe that we contrived at the beginning. We treat nature as essentially a Turing machine, ${ }^{65}$ that is, as a mechanism with a defined output for every input. We give the universe a certain input, and we expect a defined output. And we assume that we can deduce the machine's axioms of operation from the responses we get to particular inputs. Of course we know that whatever kind of machine the universe is, it cannot be a machine of this type. But this logic allows us to systematically construct a workable, if incomplete, model of how the world functions. ${ }^{66}$

Some of you who know something of such matters may protest that quantum mechanics does not function in this way; at the atomic scale, material behaves in seemingly unpredictable ways so that we cannot definitely determine both its position and velocity, and sometimes things pop up in places without troubling to inhabit, even temporarily, the spaces between where they were and where they are. But this only means that we are talking about a probabilistic machine, and not that we are no longer talking about a machine. There is still an input, a process, and an output, even though we may state the inputs and outputs as statistical ranges. Others may protest with a bit more sophistication that Gödel and Turing have shown that the universe cannot be quite this kind of a machine; that such a system would be incomplete or inconsistent. ${ }^{67}$ But here we are talking simply about the

${ }^{65}$ MARVIn Minsky, COMPUTATION: Finite AND Infinite MACHINES 117 (1967) (“A Turing machine is a finite-state machine associated with an external storage or memory medium.").

${ }^{66}$ See JACOB BRONOWski, The Laws of Nature and the Nature of Laws, in THE ORIGINS OF KNOWLEDGE AND IMAGINATION 65, 80 (1978).

${ }^{67}$ See JACOB BRonowski, The Logic of the Mind, in The IDENTITY of MAN 117, 124 (Natural History Press rev. ed. 1971) (1965). 
limits of our ability to describe the universe as a formal system; at some point it is undoubtedly true that at some point the axiomatic system of science, and the language of science, mathematics, will break down. This has not stopped science from making falsifiable predictions about the behavior of the universe, and while we may at any moment find the limits of the system, on the whole it continues to work pretty well.

The logic of copyright, the logic of expression, however, is indeed quite different. It effectively assumes that originality, the touchstone for copyrightable subject matter, stands outside the causal order of the universe. It is part of the romantic view. A considerable body of scholarship has now explored the myth of the "romantic author," a sort of fictional, solitary genius from whose fevered brow original expression springs full-blown, like Athena from the head of Zeus. This authorial caricature, drawn from a nineteenth century vision of creation, continues to animate copyright law with the assumption that creative expression originates from an isolated creator. ${ }^{68}$ Much of postmodern copyright criticism has been concerned with pointing out that there can be no creation of expression ex nihilo, that writers and artists are situated in the communities in which they create, and draw upon the influences with which they are surrounded. Yet the cult of the romantic author persists, perpetuating legal rules that inflate the exclusive rights of the author at the expense of the public, and which alienate the creative process from the sources that creation necessarily draws upon. ${ }^{69}$

Now this body of scholarship might initially appear at odds with the observations I have been making here; to say that copyright valorizes the independence of the romantic genius when I have been saying that copyright incorporates assumptions of determinism. But the two are in fact complementary. Copyright adopts, as counterpoint to the romantic author, an almost classical positivism, which owes less to $\mathrm{Mach}^{70}$ and Carnap ${ }^{71}$ than it does to Laplace ${ }^{72}$ and Comte. ${ }^{73}$ I have remarked elsewhere on the strain of Cartesian dualism that permeates the law of copyright, separating mind from matter, conceptual from material. ${ }^{74}$ And now here it is again. Romanticism draws the boundary of copyright to include that which is original to the author and exclude that which derives from

${ }^{68}$ See, e.g., Peter Jaszi, Toward a Theory of Copyright: The Metamorphoses of "Authorship," 1991 DUKE L.J. 455, 455-56; Martha Woodmansee, On the Author Effect: Recovering Collectivity, 10 CARDOZO ARTS \& ENT. L.J. 279, 279 (1992).

${ }^{69}$ See David Lange, At Play in the Fields of the Word: Copyright and the Construction of Authorship in the Post-Literate Millennium, 55 LAW \& CONTEMP. PROBS. 139, 141-42 (1992).

${ }^{70}$ See JOHN T. BlaCKMORE, ERNST MACH: HiS WORK, LIFE, AND INFLUENCE (1972).

${ }^{71}$ See Alan W. Richardson, CarnaP's CONSTRUCtion OF the WORLD: THE AUFBAU AND THE EMERGENCE OF LOGICAL EMPIRICISM (1998).

${ }^{72}$ See HAHN, supra note 7.

${ }^{73}$ See MARY Pickering, Auguste Comte: An InTEllectual Biography (1993).

${ }^{74}$ See Dan L. Burk, Feminism and Dualism in Intellectual Property, 15 AM. U. J. GENDER SOC. POL'Y \& L. 183, 185 (2006). 
material causality. Original expression arises out of the author; fact and measurement exist outside of the author. Copyrightable expression derives from unfettered will; uncopyrightable fact and measurement are bound to the condition of the world.

For all the talk of the romantic author, and how that concept defines the subject matter of copyright, there has been little recognition that it also necessarily defines that which is excluded from copyright. That which is original, which springs from genius, defines that which is unoriginal, which exists already in the state of the world. If the original expression in copyright constitutes that which is animated by romantic genius, then the methods, processes, and facts which are excluded from copyright must constitute inert mechanics, devoid of such genius. The two go hand in hand; if the zeitgeist of the eighteenth and nineteenth century defines that which is protected by copyright, then the definition of that which is excluded from copyright arises out of the same milieu. And if the cult of the author has been left untouched by postmodern recognition that no one creates expression in cultural isolation, so too copyright's conception of fact has been left untouched by postmodern recognition that no material process is realized in cultural isolation.

This view of the universe is implicit in cases, such as $C C C$, that incorporate a deterministic logic into their reasoning over copyrightable subject matter. The decisions in these cases rest upon the assumption that there are multiple ways to construct a valuation of a coin or a used car. The cases rely upon the available degrees of freedom as a proxy for originality, and for the subject matter of copyright. If, for purposes of automobile valuation, the country could be divided into six regions rather than five, or antique coins could be grouped in twelve-year increments rather than ten-year increments, then such "choices" indicate multiple approaches to an outcome, and selection among such choices must be original. Multivalent outcomes are characteristic of originality, and multivalent, nondeterministic outcomes are characterized by authorial choice, so the courts conclude that originality is signaled by the presence of authorial choice.

That syllogism is of course an error in logic, but more importantly, it is an error in perception. The question is not the presence of choice, but the kind of choice. As we have seen, in a case like CCC the distinction over choice is to some extent illusory-it is not at all clear that there are multiple ways of constructing a particular valuation of a used car, at least not if you wish that valuation to correspond to the actual state of affairs in the used car market. By the same token, it is as a practical matter unlikely that there really are multiple ways of constructing a particular symphony by Copeland ${ }^{75}$ or picture by Vasarely. You either have the unique synaptic architecture of Aaron Copeland, or you don't. But this distinction between monovalent and multivalent outcomes, which the courts inelegantly have equated with selection or choice, attempts to capture a profound difference between the informational character of a Copeland symphony and the informational character of a used car valuation. There are two very different kinds

${ }^{75}$ See generally Howard POLLACK, AARON COPELAND: THE LIFE AND WORK OF AN UNCOMMON MAN (1999) (discussing the works of Aaron Copeland). 
of information at issue here, one of which is the proper concern of copyright and one of which is not.

As Bronowski observed many years ago, every child taking geometry rediscovers the Pythagorean theorem, but they all do so in exactly the same form; there is as a practical matter only one way in which it will work. ${ }^{76}$ This is not so for a work of art or of drama, like the Mona Lisa or like Oedipus Rex. As I said in my description of the idea/expression distinction, many original portraits may be painted, many plays can be written on the same themes as contained in those works, yet no artist or playwright will express those themes quite like Leonardo or like Sophocles. Indeed, no two members of an audience viewing the Mona Lisa or Oedipus Rex will receive or understand the artist's expression in quite the same way. This is one reason that we are willing to grant exclusive rights to original expression, but not to facts and natural principles; ${ }^{77}$ we must all share the same meaning for the Pythagorean theorem, but we may each find our own meaning in Oedipus Rex.

To be sure, a Riemann ${ }^{78}$ or a Gauss ${ }^{79}$ or a Lobachevsky ${ }^{80}$ may take his own idiosyncratic view of the Pythagorean theorem, and when one of them refuses to accept that the internal angles of a triangle must add up to 90 degrees, then the assumptions of planar geometry give way and a new geometry is born: hyperbolic, parabolic, spheroid. ${ }^{81}$ That is creativity of the same order as that of a Leonardo or a Sophocles, and may well be the common characteristic that constitutes genius. But the avenues for such geometric genius are constrained in ways that the avenues for interpretation of expression are not. In all but a very few cases, the idiosyncratic treatment of basic geometry is not genius, it is simply wrong, and the geometry teacher marks the paper down on criteria that are constrained in ways that the evaluation of the teacher of painting or literature are not.

This constraint comes about because the Pythagorean theorem conveys a descriptive statement about the external state of the world, whereas Oedipus Rex

${ }^{76}$ JACOB BRONOWSKI, On Art and Science, in A SENSE OF THE FUTURE 16, 18 (1977).

77 There is a real question as to whether a mathematical statement such as the Pythagorean theorem constitutes a fact or a natural principle. See PHILlIP J. DAVIS \& Reuben Hersh, The MATHEMATICAL EXPERIENCE 321 (1980). At a minimum it constitutes a statement that is constrained in equivalent formulations. See Robert G. Balding, A Socratic Approach to Understanding the Limits (if Any) of Software Copyright Protection, 28 JURIMETRICS J. 153 (1988).

${ }^{78}$ See generally JOHN DERBYSHIRE, PRIME OBSESSION: BERNHARD RIEMANN AND THE Greatest Unsolved PROBLEM In MATHEMATICS (2006).

${ }^{79}$ See generally M.B.W. Tent, ThE Prince OF MATHEMATICS: CARL FriEdrich GAUSS (2006).

80 See generally Alexander Vucinich, Nicolai Ivanovich Lobachevskii: The Man Behind the First Non-Euclidean Geometry, 53 ISIS 465 (1962).

${ }^{81}$ For a lay introduction to non-Euclidean or differential geometries, see MICHAEL Guillen, Bridges to Infinity: The Human Side of MAthematics 84-86, 108-111 (1983). 
conveys, at base, a statement about the internal state of the self. ${ }^{82}$ I might add that hyperbolic or spheroid geometry is also a description of the external world, it is simply a different external world than that of Euclid, although if we believe Einstein perhaps not different than the world in which we live. We use such descriptions prescriptively in the logic of science, to make predictions about how the universe will react when we bring it to an experimental crossroads. We rely upon them as functional descriptions to construct the useful articles and processes that are excluded from copyright but included within the patent system. They are, as Karl Popper would have said, ${ }^{83}$ testable and falsifiable; they either work or they do not.

This is not at all the case for those works that copyright would call original expression. The information conveyed by such works is information of a very different kind than conveyed in a scientific work. I said before that we might write many works on the theme of Romeo and Juliet. But the point of Romeo and Juliet is not to make a recommendation as to whether you should fall in love with your hereditary enemies, nor as to whether thwarted lovers should commit suicide, anymore than the point of DaVinci's "Last Supper" is to convey a historical depiction of a meal taken in an upper room of first-century Jerusalem. ${ }^{84}$ Such works do not carry, except incidentally, an objective message about the physical world or its deterministic functions. They carry instead a subjective message about the experience of being human; at a minimum something of the author's experience, but just as important, something we recognize of ourselves. ${ }^{85}$ Indeed, although this article is not intended as an exposition on aesthetics, ${ }^{86}$ C.S. Lewis once asserted that the dividing line between good literature and bad literature, between art and kitsch, is that capacity to expand the reader's experience. ${ }^{87}$ Good literature, he said, conveys something to the audience outside of their previous experience, whereas bad literature is merely a vehicle used by the audience to reenforce their own preconceptions and prejudices. ${ }^{88}$ It is the transformative potential of the work that makes all the difference.

Having drawn that distinction, perhaps it becomes clear how profound an error the court made in $C C C$. Estimates of used car value are manifestly information of the descriptive, prescriptive type, and not reflections on the implications of the evaluator's experience, or an elegy on the state of humankind. The Red Book tables provide testable and falsifiable predictions about the value of used automobiles and a recommendation as to how one ought to act-what one

82 JACOB BRONOWSKI, The Logic of the Mind, in THE IDENTITY OF MAN 51, 64-65 (Natural History Press rev. ed. 1971) (1965).

${ }^{83}$ See generally KARL R. POPPER, THE LOGIC OF SCIENTIFIC DISCOVERY (1959).

${ }^{84}$ Cf. id.

${ }^{85} \mathrm{Id}$.

${ }^{86}$ But see Alfred C. Yen, Copyright Opinions and Aesthetic Theory, 71 S. CAL. L. REV. 247, 247-51 (1998) (arguing that sound copyright reasoning should incorporate aesthetic reasoning).

${ }^{87}$ C.S. LEWIS, AN EXPERIMENT IN CRITICISM 14-21, 88-94 (1961).

${ }^{88} \mathrm{Id}$. 
ought to pay-in the market for used automobiles. While the value estimate may have been the result of choices, those choices were profoundly constrained by the logic of science, by the need to conform to the state of the external world. If we can imagine another Red Book, or a Green Book or a Pink Book, based on a different set of choices with a different set of estimates, it is either because, like the departure of Reimann or Lobachevsky from Euclidian geometry, they provide a closer fit to external criteria; or it is because, like the paper of the erring geometry student, those alternate estimates are simply wrong. Market estimates and valuations may be demonstrably wrong; Shakespeare and Sophocles never are. The messages of Shakespeare or Sophocles may be impenetrable, or unappreciated, or even immoral, but they are never wrong in any scientific sense of the word.

\section{PATENT LAW INTERMEZZO}

Now we leave copyright, just for a moment, just for the sake of perspective. It is worth pausing to consider that a parallel problem arises in patent law, which is in many senses the complement to copyright. A comparison between the two may seem rather odd given what I have been saying about copyright: that the subject matter defined by the patent statute explicitly includes processes, ${ }^{89}$ whereas I have made a great deal of the fact that the subject matter defined by the copyright statute explicitly excludes processes. One of the messages of Baker v. Selden was that methods and processes belong in patent law, if they belong anywhere. So it seems odd that patent law would have difficulty accommodating process claims when by definition it is intended to include them, or that patent protection of processes would have anything to teach copyright when by definition it is not.

But the inclusion of processes within the stated subject matter of the patent statute does not mean that patent law can distinguish process inventions from nonprocess inventions, or that it knows what to do with processes when it finds them. Following the statute, patentable inventions are traditionally lumped into the categories of process inventions and product inventions, the latter covering the statutory subject matter of manufactures, machines, and compositions, and the former being the immaterial odd category out. Processes themselves are typically divided into methods of making and methods of use: the kinds of processes one can engage in with some material object. But since the exclusive rights conferred under product patents include the rights to make and use the claimed invention, those processes are always entailed within the grant of a patent on a material object anyway.

These categories and distinctions made some sense and worked relatively well until recently. I have detailed elsewhere the difficulties that courts and the Patent Office have had in distinguishing product from process, particularly in the biotechnology area, and to some extent in computer software as well. ${ }^{90}$ Since the

8935 U.S.C. $\$ 101$ (2006).

${ }^{90}$ Dan L. Burk, The Problem of Process in Biotechnology, 43 Hous L. REV. 561, 562-66 (2006). 
Supreme Court initiated the age of biotechnology patenting with its decision in Diamond v. Chakrabarty ${ }^{91}$ a good quarter-century ago, the patent system has repeatedly run up against difficulties in separating product from process. This problem has occurred across a variety of patent doctrines, such as determining the patentability of a novel product produced by means of a previously known process, or determining whether the offshore use of a patented product in a non-infringing process could constitute infringement, or determining the utility of a process that yields a product of indeterminate use. ${ }^{92}$

I have argued that the difficulty in separating process from product in these cases stems first from the nature of processes and second from the nature of technologies that have recently become patentable. ${ }^{93}$ Processes involve the transfer of information, as that term is defined in physics and related disciplines-a measure of the state of uncertainty or disorder in a particular system. ${ }^{94}$ This definition is held to be true for all types of physical processes. It is the basis for a number of scientific laws that we have formulated to describe the behavior of the universe, as well as being increasingly the basis for our understanding of the nature of the fabric of the universe itself. We conceive the universe as comprised of material, which take the form of either matter or energy, and of information, which orders the arrangement of that material. ${ }^{95}$ The information may be in a state of dynamic transfer or the information may be in a state of static embodiment.

This understanding of process and product explains why in previous technologies we could draw a clear distinction between the two categories; we could focus on the material, and ignore the informational nature of the invention. But this is not the case for the problematic new subject matter categories of biotechnology and computer software. In these technologies information is only lightly embodied, lies very near the surface of the material instantiation, and is quite impossible to ignore. In these technologies process shades into product because the transfer of information cannot be easily distinguished from the information itself. And when products become largely indistinguishable from processes, the distinctions among product patents and process patents become increasingly untenable.

So there has been in patent law what we might call a kind of merger, if we are willing to borrow some copyright terminology. The information conveyed in a process can no longer be distinguished from the process itself. The courts have responded to this development by declaring utility to be the key criterion for patentable subject matter, by saying that any process which produces a useful

${ }^{91} 447$ U.S. 303 (1980).

${ }^{92}$ See Burk, supra note 90.

${ }^{93} \mathrm{Id}$. at $588-90$.

${ }^{94} \mathrm{See}$ John R. Pierce, An Introduction to Information TheOry: Symbols, SignALS, \& NOISE 24 (2d rev. ed. 1980).

95 See Lee Smolin, Three Roads to Quantum Gravity 55-56 (2001); see also Jacob D. Bekenstein, Information in the Holographic Universe, SCI. AM., Aug. 2003, at 58, 58. 
outcome is potentially a patentable process. ${ }^{96}$ This response effectively does away with what we might call the fixation requirement for patents, with any requirement that a process be instantiated in a physical apparatus. And so purely informational processes become patentable, which is why we hear so much commotion about the patenting of business methods and other nontechnical methods. ${ }^{97}$ If purely informational processes are patentable, then perhaps it does not matter so much what is a product and what is a process, but the doctrinal categories built up around these distinctions are bound to become troublesome. ${ }^{98}$

In light of this breakdown in patent law categories, reconsider the problem that processes pose for copyright. In the case of copyright, we deal with creative works that are purely informational; by statutory definition, copyright is directed to the expressive work embodied in a particular tangible object, but not to the object itself. $^{99}$ And yet the information comprising the intangible work must be of an idiosyncratic nature: communication of facts or other unadorned representations of the universe lie outside the realm of copyright. So the statute simultaneously requires us to separate the material from the intangible and the utilitarian from the aesthetic, for example defining the uncopyrightable useful article ${ }^{100}$ as an item that does not merely convey information or portray its own appearance. Recall that Baker tells us useful articles and other functional items belong to patent law.

The copyright act excludes processes; Baker declares them to be the subject matter of patent law. The implication is that processes are by definition utilitarian, because of course utilitarian subject matter is the domain of patents. Causation

${ }^{96}$ State St. Bank \& Trust Co. v. Signature Fin. Group, Inc., 149 F.3d 1368, 1375 (Fed. Cir. 1998).

${ }^{97}$ See Rochelle Cooper Dreyfuss, Are Business Method Patents Bad for Business?, 16 Santa Clara Computer \& High TeCH. L.J. 263, 265 (2000); Leo J. Raskind, The State Street Bank Decision: The Bad Business of Unlimited Patent Protection for Methods of Doing Business, 10 Fordham InTELL. Prop. Media \& ENT. L.J. 61, 62 (1999); John R. Thomas, The Patenting of the Liberal Professions, 40 B.C. L. REV. 1139, 1141-42 (1999).

${ }^{98}$ Some panels of the Court of Appeals for the Federal Circuit appear to have begun acknowledging this tangibility problem, and are now desperately trying to distance themselves from the consequences of the State Street decision, perhaps fearing unwanted attention from the Supreme Court. Compare In re Comiskey, No. 2006-1286, 2007 WL 2728361, at *6-7 (Fed. Cir. Sept. 20, 2007) (holding a method of arbitration unpatentable), and In re Nuijten, No. 2006-1371, 2007 WL 2728397, at*5 (Fed. Cir. Sept. 20, 2007) (holding an encoded electromagnetic signal without apparatus unpatentable), with Lab. Corp. of Am. Holdings v. Metabolite Labs., Inc., 126 S. Ct. 2921, 2928 (2006) (Breyer, J., dissenting from the dismissal of the writ of certiorari as improvidently granted) (questioning whether the State Street decision comports with Supreme Court precedent regarding intangible processes). But it is unclear how one can draw a subject matter line that avoids the doctrinal endpoint reached in State Street. See Dan L. Burk \& Brett H. McDonnell, Patents, Tax Shelters, and the Firm, 26 VA. TAX ReV. 981, 984 (2007) (noting that software patenting leads inevitably to patents for intangible processes).

${ }^{99} 17$ U.S.C. § 202 (2006).

${ }^{100} I d . \S 101$ (defining "useful article"). 
involves the transfer of information. ${ }^{101}$ Sometimes that information will be communicative and sometimes it will be static. When it is communicative, it may sometimes be factual, reflecting the external state of the world, or sometimes that information will be expressive, reflecting the internal state of humankind. But in any event, copyright has always assumed that you can separate the process of transfer from the information transferred, and that the process of transfer is always utilitarian or functional.

This exclusion, which is really the best way to think about the result in Baker, makes a good deal of sense when your processes are embedded in physical apparatus, when the process is tangibly fixed. We know that such an apparatus, of cogs and gears and wires does not belong to the copyright system. But the distinction is much less viable when we are dealing with purely informational processes that are only lightly fixed, if at all, so that the information is very nearly free of material embodiment. As in patent law, software presents this kind of profile to copyright law. The valuation methods in $C C C$ and $C D N$ are processes of the same type; even if the courts are correct that they are too subtle to be captured as computer code, they are informational processes running in a carbon-based processor rather than in a silicon-based processor.

\section{DETERMINED TEXTS}

Let me review the argument up to this point. We began with several propositions of black-letter copyright law, harking back to Baker v. Selden, that copyright does not protect ideas, utilitarian items, processes or methods. We then reviewed several recent cases that seem to do the last, to protect a process or a method by protecting as a matter of copyright law the output of that process or method-to protect the methodology of valuation by protecting a statement about the value of a coin, or of a used car. The justification or rationale given in these cases is that the method or process was creative, where creativity is defined as selecting steps in the process from among other alternatives.

These cases and their justification are troubling, but we know that neither the objection to them nor the defense of their outcome can be quite right. The objection cannot be quite right because every copyrightable work is the result of some process, so that for copyright to effectively protect an underlying process by protecting its result may actually be quite common. The rationale justifying the outcome cannot be quite right because the results of these particular processes were clearly intended to accurately represent or reflect the state of the world. In short, the output of the processes was certainly intended as fact.

This in turn leads us back again to a black-letter proposition of copyright law: that copyright does not protect facts. But these cases we are considering throw into doubt the characterization of facts; they appear to assert that whatever facts may be, they are not derived from creative choices among alternatives. In other words,

101 Cf. John Collier, Causation Is the Transfer of Information, in CAUSATION AND LAWS OF NATURE 221-23 (Howard Sankey ed., 1999). 
facts are the result of certain methodologies. The corollary to this supposition seems to be that facts are entities that somehow exist independent of human creativity and judgment. Both versions of the supposition are of course absurd; any description of the world is in fact a judgment, and the result of creative choices. So if the application of human choice or judgment is our criterion, then facts cannot be excluded from copyrightable subject matter; copyright would cover them all.

The black-letter copyright rule for excluding facts holds that they are not original, that is, that they do not originate with the author. This distinction arises from a romantic view of authorship which has been elucidated and critiqued in detail by a host of scholars, who have pointed out how this view aggrandizes the capture of cultural properties and ignores the communal milieu of creation. The view that creativity springs from the mind and will of the solitary genius sits well with neither postmodern theory of the arts nor with what we know empirically and anecdotally about the creative act. ${ }^{102}$ The artist is not separate from either the natural or the cultural environment; there must be creative inputs before there can be creative outputs.

But the same is true of science, of the methodology by which we generate and certify facts, both in the creation of theories and in the measurements that we call experiment, which allow us to distinguish between more or less preferable theories. The scientific method requires creative choices, requires creative inputs, to formulate empirical theories and subject them to experiment. This is not to say that we must embrace the romantic view of authorship in order to exclude facts from the subject matter of copyright; it is rather to reject the criterion of selection as the determinant for copyright. The question is rather whether a particular work must conform to a determined outcome. Copyrightable expression is not constrained in this fashion; it communicates something about the state of the self, rather than something about the state of the world. ${ }^{103}$ The purpose of Hamlet is not to advise us on whether or not to avenge our father's death, any more than Frost's poem Mending Wall is intended to advise us on whether to be friendly with our neighbors. ${ }^{104}$ On the other hand, the purpose of the used car Red Book is decidedly to advise us on whether or not we are paying too much for a particular used car, and guides to antique coins or options contracts have a similar function.

Let me be clear in my assertion. I am not asserting that we need accept the fiction of the romantic author, nor yet that we must treat science as the product of such romance. I am rather asserting that the exercise of judgment cannot be the point upon which we distinguish what we call fact from what we call original expression. This recognition leads us to the proper criterion for exclusion: that the proper subject matter of copyright is multivalent, rather than monovalent. That distinction is drawn ultimately from the core insight of Baker v. Selden and its

${ }^{102}$ See Julie E. Cohen, Creativity and Culture in Copyright Theory, 40 U.C. DAVIS L. REV. 1151, 1151-54 (2007).

${ }^{103}$ Cf. BRONOWSKI, Knowledge of Self, in THE IDENTITY OF MAN, supra note 82, at 64-69.

${ }^{104}$ Id. at 72. 
progeny: where there is only a single or limited mode of expression, we will not grant an exclusive right in that mode. If you wish we can view it as an originality criterion: there is nothing original in expressing a work in the only way it can be expressed, where the choice is imposed on the author by necessity, not by any act of creativity.

In the case of valuation procedures for cars or coins, the courts implicitly adopt the position that if the choice of value is imposed upon the creator by necessity, it is not a creative choice, and was chosen for the sake of conforming to the state of the world. They then assume that because the creator is free to indulge in fantastic or inaccurate valuations, he is under no constraint. As a criterion for creativity this is quite mistaken; but stripped of this error, the underlying logic of monovalence may be helpful. It is the characteristic of determinism, of a single constrained outcome, that is the common thread among the black letter exclusions from copyrightable subject matter. Merged expression cannot be included within copyright because it is limited to a single instantiation; facts cannot be protected because they are constrained to a single result. Processes, methods, and systemswhich is to say, in effect, machines - cannot be included because they are quite literally geared to a particularized output.

A moment ago I mentioned software in the context of patent law, and alluded to the problems it poses for copyright. It should now be clear why that is so. The use of selection as a proxy for determination, the failure to recognize multivalence rather than choice as the criterion for copyright, can only work mischief with the copyright system. That problem is certainly manifest in $C C C$, but reaches its zenith in the computer cases from the 1980s and 1990s. The courts in those cases were attempting to accommodate software within the copyright act, as Congress has instructed them to do. Following those legislative instructions was really a logical impossibility, as the statute specifically forbids copyright protection for methods and processes, and yet software comprises a method or process. In the key decisions, such as Apple v. Franklin, ${ }^{105}$ the courts attempted to separate the symbolic representation of a process from its physical execution, holding that the former was protected by the copyright statute, whereas the latter was not. This bifurcation had long been the staple logic for dealing with cooking recipes and such; the words describing the culinary process might fall under copyright, but the execution of the process described by the words was not. ${ }^{106}$ In other words, the copyright statute defines computer programs as "instructions" to a machine, ${ }^{107}$ and courts attempted to treat instructions to a machine as you would treat instructions to a human. ${ }^{108}$

105714 F.2d 1240, 1253-54 (3d Cir. 1983).

${ }^{106}$ See, e.g., Publ'ns Int'1, Ltd. v. Meredith Corp., 88 F.3d 473, 480-81 (7th Cir. 1996).

10717 U.S.C. $§ 101$ (2006).

${ }^{108}$ Dennis S. Karjala, Copyright, Computer Software, and the New Protectionism, 28 JURIMETRICS J. 33, 41-42 (1987). 
But this of course would not work, because the computer code specifies a process that is entirely deterministic in the sense that we have been talking about. We euphemistically call the program a set of instructions, but they are not instructions of the sort that a cook reads in a recipe, calling for a teaspoon of sugar, but for which the cook may choose to substitute half a teaspoon of sugar, or a teaspoon of honey, or no sugar at all. ${ }^{109}$ When executing computer code, the machine exercises no judgment, has no choice in whether a certain set of bits will be moved to a particular register; or viewed at a different level, has no choice whether a certain voltage will be raised or lowered across a certain circuit. The courts hoped to treat the code as a sort of notation for a blueprint of certain circuit configurations. But where software is concerned, the separation between specification and machine is not so neat: when placed in the context of hardware, the software notation does not merely describe the circuit, it in fact configures the machine so as to become the circuit.

Commentators have tried to capture this principle by describing software either as "text that behaves" or as "a machine built of text." "110 Usually we think of machines as built out of metal, plastic, or other physical substances, and a hardwired data processor is in fact constructed wholly of such materials. But we have decided to construct the majority of our data processing devices as universal machines that can be reconfigured for different purposes by a text that the programmer composes. Indeed, Phil Agre has pointed out that therein lies the enormous power of the modern computer: because such machines are quite literally inscribed with text, anything that can be described can be modeled virtually as a computing process. ${ }^{111}$ For our purposes here this is significant because construction of a device by writing text is equivalent to constructing the device by soldering metal or molding polymers: both will execute processes to produce a determined, monovalent outcome. The execution of the physical process becomes coterminous with the symbolic specification of the process.

Either definition of software contemplates a mechanism whose operation yields a certain result rather than that of an expressive text with variant possible articulation and interpretation. We can perhaps try to push the question of choice back a level, and say that the programmer made a judgment, or had choices in selecting the functions that would be specified by the computer code she wrote. This, by the way, is most likely how the copyright law tries to deal with works of computer-generated art: by assuming that the author, the entity who made choices about the output, is not the machine, but is rather the programmer who created the

\footnotetext{
${ }^{109}$ See id.

${ }^{110}$ Pamela Samuelson et al., A Manifesto Concerning the Legal Protection of Computer Programs, 94 ColuM. L. REV. 2308, 2320 (1994).

${ }^{111}$ See Philip E. Agre, Internet Research: For and Against, in INTERNET RESEARCH ANNUAL: SELECTED PAPERS FROM THE ASSOCIATION OF INTERNET RESEARCHERS CONFERENCES 2000-2002, at 25, 27 (Mia Consalvo et al., eds., 2004).
} 
software driving the machine. ${ }^{112}$ But in the case of most commercial software, if perhaps not in the case of computer generated art, the programmers choices are constrained in the same ways that the valuations in $C C C$ or $C D N$ were constrained: by the functional goal of the specified process. Choices in programming are constrained by the limits of the hardware; speed, efficiency, capacity of the processor and memory. This is the same situation as that in Batlin; the constraints of the material dictate the design of the work, and the result is the same as well: the outcome is not original as copyright defines that term. In computer code, process, machine, and information come together in expression that is entirely determined by the need for congruity with the state of the world.

\section{CONCLUSION}

I said at the outset of this essay that copyright asks us to believe the outrageous, the impossible. Some of those impossibilities are readily apparent, but others come to light only with a little digging. It was perhaps not immediately obvious at the beginning of this essay that we would find embedded in the copyright statute a powerful and somewhat loaded philosophical assumption regarding the nature of reality. Copyright assumes that certain types of outcomes, certain types of results, are determined or constrained or monovalent, and that those types of mechanistic outcomes lie outside the subject matter of copyright. The universe is a machine, and human artifacts which rely on that mechanism, which are in effect piggy-backed on the functioning of the cosmic machine, belong to the realm of patent law.

This bifurcation of patent and copyright, as held in Baker v. Selden, is structured around the separation of function and expression into separate compartments. It turns upon a mechanistic view of process or method. But as I have argued in the previous work I mentioned, we have begun to discover in patent law that this neat separation cannot be sustained, as informational technologies such as software and recombinant DNA strain the definitions of process and product, of machine and expression. If this has become apparent in patent law, the same must be true for the paired body of law intended to accommodate expression. As the other bookend to patent law, copyright shares the categorical breakdown between process and information. You can no longer rely on the separation of process and information to keep functional subject matter out of copyright. So you have to pay rather careful attention to the type of information at issue, as it may be expressive information that belongs to copyright after all.

But perhaps the most startling realization about copyright's concept of determined outcomes is that it exists in the statute alongside the romantic view of original authorship. Copyright does not merely adopt the positivist view, I might say the somewhat tautological positivist view, that the universe is the sum total of

112 FinAL REPORT OF THE NATIONAL COMMISSION ON NEW TECHNOLOGICAL USES OF COPYRIGHTED WORKS 44 (1978), available at http://digital-law-online.info/CONTU/PDF/ index.html. 
the observations about the universe and nothing else. ${ }^{113}$ Copyright adds to this the rather mystical proposition that there is something outside the mechanism of nature, something that is not a fact or observation, something that arises out of human creativity, and which is the proper subject matter of copyright. I said at the beginning that in this discussion we would skirt the quagmire of free will and determinism, but it is there nonetheless; and if original expression stands somehow outside the causal order of the universe, there remains for some future investigation the problem of the nature of the subject matter the copyright statute is constructed to protect.

Now there may be some tendency to ask why we need to unpack everything from these cases in this way, to ask what all the fuss is about. There may be some tendency to say, well, the courts in these cases are simply trying to protect people's investment in valuable creations, and well they should. You might say to yourself that a case like $C C C$ is really just about courts trying to reach an optimal business result, and even if the reasoning is a little muddy, the outcome is all that matters. We don't need to understand determinism and multivalence and such to go on protecting investments in car valuations or coin valuations. That is the only guiding rule we need, to protect and encourage economic incentives, and that should be explanation enough for anyone.

Economic justifications for intellectual property statutes are very popular today, and they are fine so far as they go. I have certainly done some of that kind of analysis myself. ${ }^{114}$ But if that is all that we are trying to accomplish, then there really is no need for anything as complex as the copyright statute, with all of its apparatus about expression and originality and so on; we could instead use a much simpler general misappropriation statute to protect people's investment in creativity (and indeed, Professor Litman has suggested that perhaps we ought to do exactly that). ${ }^{115}$ So that cannot be the whole story. While encouraging investment may be an objective of the statute, what we have seen here is that it is by no means the only objective of the statute. Given the assumptions that we have seen embedded in the statute, it may not be very well suited to that objective. Indeed, given what we have seen demonstrated in this essay, we can say at most that if the statute is intended to promote investment, it is directed to promoting investment in only a very particular type of subject matter. You cannot use copyright as a general misappropriation statute without doing enormous violence to the structure of the copyright system, and ignoring all of the limiting parameters that the statute lays out. Which is of course unfortunately exactly what the opinion in $C C C$ does.

That observation leads us immediately to the "So what?" question. There is always someone in the back row-and occasionally, in the front row-of the

${ }^{113}$ See A.J. Ayer, Editor's Introduction, in LogicAl Positivism 3, 11-12 (A.J. Ayer, ed., 1959); see also MiCHAEL FrIEDMAN, RECONSIDERING LOGICAL POSITIVISM (1999).

${ }^{114}$ See, e.g., Dan L. Burk \& Brett H. McDonnell, The Goldilocks Hypothesis: Balancing Intellectual Property Rights at the Boundary of the Firm, 2006 U. ILL. L. REV. 275.

115 See Jessica Litman, Revising Copyright for the Information Age, 75 OR. L. REV. 19, 47-48 (1996). 
lecture hall who asks the "So what?" question when the lights come up at the end of a presentation. What difference does all of this make, he asks? If this is your analysis, then what are your recommendations? How should this change our current practice? What ought we to be doing differently?

There is of course the answer that we ought to value new knowledge for its own sake; that, in this particular instance, we are better off understanding the nature of the assumptions in the copyright statute than we are not understanding them. In most disciplines, that answer is enough. If the fund of human knowledge has been enriched, then everyone is satisfied. If pure research becomes applied, so much the better, but that is not the point of it. I think that answer a perfectly adequate answer, but perhaps it will not do in this case. In law we always want to do something with our conclusions. It is something drummed into us very early in legal education. That is after all the method of prototypical student law review note: identify a problem, explicate it, and propose legislation to solve it. Tie the package up neatly.

With apologies to the law review students, I am not about to propose legislation. Most of the problems that we have already in copyright law are the result of someone proposing legislation. ${ }^{116}$ Each time legislation is proposed, we get a few more problems, and only rarely solve the problem that we meant to solve with the proposal. ${ }^{117}$ The anomalies I have pointed out here will not be resolved by legislation in any event. They are inextricably intertwined with every aspect of copyright as we know it. If we are unhappy with the underlying philosophy of the current statute, we will probably have to do away with the statute altogether. And perhaps Professor Litman is correct that we should do exactly that. But even then we will simply be substituting one set of philosophical assumptions for another. Every statute has embedded assumptions, and since we now know something more about the assumptions in our present statute, perhaps we should stick with the ones we know.

So as long as we have the current statute, it is not clear that we should $d o$ anything about its underlying assumptions, or at least, that we should do anything other than recognize and accept their presence. It is claimed, probably apocryphally, that Einstein defined madness as repeating the same action but expecting different results - or in other words, as ignoring determined causality. But it is equally mad to engage in differing actions and expect a consistent result. This is what the courts have been doing. Courts must be aware of the logic of copyright in order to reach results that are consistent with that logic, which I think I have demonstrated that the valuation cases decidedly are not. The value of unearthing the doctrinal structure, the reason for all the fuss, is that we must know

116 Jessica Litman, Copyright Legislation and Technological Change, 78 OR. L. REV. 275, 277 (1989); Jessica D. Litman, Copyright, Compromise and Legislative History, 72 CORNELL L. REV. 857, 857 (1987).

117 See Dan L. Burk, Reflections in a Darkling Glass: A Comparative Contemplation of the Harvard College Decision, 40 CANADIAN BuS. L.J. 219 (2003) (discussing the downside of legislating specialized solutions in intellectual property). 
what we are about, know the underlying assumptions of copyright, if we are ever to take some of the madness out of method in copyright law. 